\title{
"Pessoas aparecem sinalizando e fica algo bem próximo a realidade": o software Lepê como possibilidade para uso do trabalho docente na educação de surdos
}

\author{
Viviane Nunes Sarmento ${ }^{1}$, Danillo Moraes Lima dos Santos ${ }^{1}$, Fagner Luiz \\ Pulça de Barros ${ }^{1}$, Cleyton Silva Batista ${ }^{1}$, Rian Gabriel Santos Pinheiro ${ }^{1}$, \\ Neiza de Lourdes Frederico Fumes ${ }^{2}$ \\ ${ }^{1}$ Universidade Federal Rural de Pernambuco \\ Unidade Acadêmica de Garanhuns \\ (UFRPE - UAG) \\ Avenida Bom Pastor - s/n - Boa Vista - 55.292-270 - Garanhuns - PE - Brasil \\ ${ }^{2}$ Universidade Federal de Alagoas \\ Av. Lourival Melo Mota - S/N - Tabuleiro do Martins - 57072-900 - Maceió - AL - Brasil \\ \{vivianesarmento2, moraesdanillo10\}@gmail.com \\ \{fagnerluizbarros, cleyton.silva.batista\}@gmail.com \\ rian.gabriel@gmail.com, neizaf@yahoo.com
}

\begin{abstract}
Bilingual education for deaf people, when these children are sons of hearing parents, has rendered into the reality that these children reach school age without mastery of the Brazilian Sign Language, a language that is systematically taught in school. In view of this situation, we created the LEPE that is a learning object to be used by the teacher in order to contribute to this teaching of Libras. This study aims to analyze the opinions of teachers specializing in the education of the deaf in the municipalities of Maceio and Garanhuns regarding Lepê, aiming to verify the possibilities of applicability and functionality of the developed software. To achieve these objectives, the software was made available for use by participating teachers in a period of three months. Subsequently, a qualitative research was carried out, using as instrument the semi-structured interview with the teachers, being 6 (six) teachers in Garanhuns and 6 (six) in Maceio. The results highlighted positive aspects about the developed software, regarding the use of contexts, "real signs" and their visual characteristics, evidenced as essential for the work in the education of the deaf.
\end{abstract}

Resumo. A educação bilíngue para pessoas com surdez, quando essas crianças são filhas de pais ouvintes, tem se traduzido na realidade de que estas acabam alcançando a idade escolar sem o domínio da Língua Brasileira de Sinais, língua referida que passa a ser ensinada de forma sistemática na escola. Diante desse quadro, criamos o LEPÊ que configura-se em um objeto de aprendizagem a ser utilizado pelo professor no intuito de contribuir para com esse ensino da Libras. Visto isto, para esse estudo objetivamos analisar as opiniões de professores especialistas na educação de surdos dos municípios de Maceió e Garanhuns acerca do Lepê perspectivando verificar as possibilidades de aplicabilidade e funcionalidade do software desenvolvido. Para alcançar tais objetivos, foi disponibilizado o software para uso dos professores participantes em um 
VI Congresso Brasileiro de Informática na Educação (CBIE 2017)

Anais do XXIII Workshop de Informática na Escola (WIE 2017)

período de três meses. Posteriormente foi realizada uma pesquisa qualitativa tendo como instrumento a entrevista semiestruturada com os professores, sendo 6 (seis) professores em Garanhuns e 6 (seis) em Maceió. Os resultados destacaram aspectos positivos sobre o software desenvolvido, em relação ao uso de contextos, "sinalizações reais" e as suas características visuais, evidenciadas como essenciais para o trabalho na educação de surdos.

Keywords: Software Educacional. Surdez. Ensino de Língua Brasileira de Sinais. Pensamento e Linguagem.

\section{Introdução}

Reconhecemos o indivíduo como um sujeito em movimento, ativo e social, onde toda a sua construção é promovida no fato deste ser histórico, perspectiva esta que impõe considerar o fenômeno social como um processo, como realidade constituída por sujeitos, ou seja"como algo que só pode ser compreendido plenamente quando se considera os sujeitos e suas possibilidades de agir, relacionar-se, produzir bens necessários à sua vida e produzir e registrar representações do objeto e de sua relação com ele"[GONÇALVES and FURTADO, 2016].

É a partir dessa perspectiva, pautada na Psicologia Sócio Histórica, em Vigostki que entedemos o indivíduo com surdez, tendo como foco o processo de construção linguística (Pensamento e linguagem). Destarte, consubstanciados no fato da grande maioria dos surdos pertencer a famílias de ouvintes torna-se imprescindível a organização de um meio linguístico adequado para este grupo e a escola torna-se ainda mais importante neste processo, visto que na maioria dos casos este acesso será realizado na escolarização.

Conforme KARNOPP and PEREIRA [2004], crianças surdas, filhas de famílias ouvintes e não conhecedoras da Libras não têm acesso aos diálogos que ocorrem no dia a dia, assim como às histórias passadas de geração a geração, contadas por seus pais.

Pensando nisso e, ao mesmo tempo, reconhecendo que essa discussão tenha crescido significativamente no Brasil, optou-se por trabalhar na perspectiva dos processos educacionais de ensino da Língua Brasileira de Sinais para surdos, inclusive porque, conforme já destacado "a grande maioria desses sujeitos alcançam idade escolar, sem domínio desta, diferenciando-se de crianças ouvintes que alcançam o processo de escolarização já inseridas no universo linguístico" [QUADROS, 2005].

Concorda-se com PEIXOTO [2006] quando afirma que é inegável a importância da Língua de Sinais aos espaços educacionais em que os surdos estão. FERNANDES et al. [2005] afirmam que:

[...] através da aquisição de um sistema simbólico como é o da língua, o ser humano descobre novas formas de pensamento, transformando sua concepção de mundo. Tendo em vlacerdaista estas colocações, torna-se bastante claro, portanto, que propiciar à pessoa surda a exposição a uma língua o mais cedo possível, obedecendo às fases naturais de sua aquisição é fundamental ao seu desenvolvimento. Privá-la desse direito, sob qualquer alegação, é desrespeitála em sua integridade.

Nesse esboço compartilhamos da ideia de que a palavra (constituída por signos) nos infunde a lembrança do seu significado, no entanto, a palavra em si não é, ou não 
VI Congresso Brasileiro de Informática na Educação (CBIE 2017)

Anais do XXIII Workshop de Informática na Escola (WIE 2017)

constitui o pensamento, entretanto, é através dela que o pensamento se realiza. Esta é uma conclusão que nos faz remeter a falha da maioria dos estudos relacionados ao pensamento e a linguagem que os consideram processos distintos, quando na verdade eles coexistem e se mantém relacionados, embora distintos.

Todavia, o que tem acontecido nas escolas regulares que recebem surdos consubstanciados na proposta do bilinguismo, segundo LACERDA [2012], são professores ouvintes que dependem de intérpretes que, em sua maioria, não possuem formação específica para a docência. QUADROS [2005] complementa quando diz que, em muitos casos, há um fazer de conta de que a língua de sinais faz parte da escola como primeira língua, não negando a sua importância, no entanto, professores que conhecem pouco a língua, terminam simplificando seu uso. Nesse sentido, pode-se dizer que há uma carência nas propostas educacionais no que tange às pessoas com surdez que são frutos da falta de conhecimentos específicos da língua, da comunidade, etc. Isso implica, conforme GESSER [2012], que aqueles que pensam sobre a escolarização de surdos deverão preocupar-se com a abordagem de ensino e com os conteúdos que contemplem esta perspectiva.

Ainda nesse sentido compreendemos que há escassez de materiais pedagógicos, voltados para práticas a serem realizadas na educação de surdos e com relação a softwares, os autores desconhecem uma ferramenta que trabalhe especificamente com a aquisição de Libras e que busquem contribuir com a atividade docente nesse sentido. As intervenções têm focado em surdos que possuem algum conhecimento em Libras e que buscam a Língua Portuguesa, ou em tradutores. Os principais softwares existentes encontrados na literatura são o HandTalk, VLIBRAS e o ProDeaf, que são em tradutores da Língua Portuguesa para Libras, realizando as sinalizações através de um avatar animado.

Diante desse quadro situacional, buscou-se trazer para essa realidade possibilidades que pudessem contribuir com esse processo. Assim, perspectiva-se, por meio da construção de uma nova ferramenta que funciona como um software, aliado/mediado pelo trabalho docente, contribuir para o ensino da Língua Brasileira de Sinais para surdos. Lembrando que o uso do software em questão não se trata de um método associativo e de tradução, mas que fora construído tendo como base a construção de signos para o desenvolvimento do Pensamento e da Línguagem [VYGOTSKY, 2000] dos alunos com surdez. Por isso, precisa ser mediado pelo professor, assim como, utilizado com base nas vivências apresentadas pelo aluno em questão, já que as tais vivências são significadas por cada indivíduo de uma forma distinta.

Para isso, foi construído um software nomeado por Lepê. O referido software possui 5 (cinco) níveis de Linguagem Compreensiva, com vocabulários distintos sinalizados por vídeo. Cada vocabulário contém a sinalização específica para a palavra (signo) que, por sua vez, possui contextos e imagens de situações baseadas em elementos o mais próximo possível da realidade do aluno. Além disso, o Lepê também dispõe de meios para avaliação dos alunos, através de uma avaliação quantitativa, onde o aluno responderá algumas questões, e uma avaliação qualitativa, onde o professor avaliará o aluno.

Uma vez finalizada a ferramenta, entendeu-se ser necessário que professores pudessem utilizá-la e, em momento posterior, realizar uma verificação sobre a utilidade e usabilidade da ferramenta proposta. Nestes termos, buscou-se responder a seguinte questão geradora: Quais as opiniões de professores especialistas na educação de surdos 
VI Congresso Brasileiro de Informática na Educação (CBIE 2017)

Anais do XXIII Workshop de Informática na Escola (WIE 2017)

do município de Maceió e Garanhuns acerca de uma ferramenta desenvolvida para contribuir com o processo de ensino de Língua Brasileira de Sinais? Pensando em alcançar tais finalidades, apresentam-se a os seguintes objetivos:

\section{Objetivos}

\subsection{Objetivo Geral}

Analisar as experiências de professores especialistas na educação de surdos dos municípios de Maceió e Garanhuns acerca do uso de uma ferramenta desenvolvida para contribuir com o processo de ensino de Língua Brasileira de Sinais.

\subsection{Objetivos Específicos}

Verificar as possibilidades de aplicabilidade e funcionalidade do software desenvolvido.

\section{Metodologia}

A pesquisa proposta foi de natureza qualitativa, pois como ANDRADE and HOLANDA [2010] indicam, este tipo de pesquisa busca conhecimentos sobre uma compreensão particular daquilo que se estuda, já que o foco de sua atenção é dirigido para o específico, o individual, aspirando à compreensão dos fenômenos estudados que somente surgem quando situados. Para alcançar tal propósito, utilizamos como instrumento entrevista semiestruturada, que foi aplicada individualmente e gravada com a autorização dos participantes através da assinatura do Termo de Compromisso e Livre Esclarecimento.

Nesses termos, após apresentação do LEPÊ aos especialistas, realizada em um momento de formação de professores na Educação Especial ofertada, foi empregada uma metodologia baseada em MACIEL and CARVALHO [2010] e LI and SMIDTS [2003] que propõem uma verificação tendo como base a opinião e/ou avaliação de especialistas da área. No caso do nosso estudo, foram 12 (doze) especialistas, sendo 6 (seis) de Maceió e 6 (seis) de Garanhuns, selecionados, após levantamento nas secretarias municipais, tendo como critério título de Mestre em Educação, especialização em Psicopedagogia, além de experiências/pesquisas anteriores na área da surdez, ou ainda atuação no Atendimento Educacional Especializado (para alunos surdos) dos municípios, além da disponibilidade para realização da pesquisa. Os professores puderam conhecer e utilizar a ferramenta por um período de teste ( 3 meses) e, posteriormente, foram entrevistados individualmente.

\section{Resultados e Discussões}

\subsection{Apresentando a Ferramenta LEPE}

Com o levantamento dos requisitos funcionais de aplicação do LEPÊ, foi realizada uma modelagem do sistema utilizando a UML (Linguagem de Modelagem Unificada), que consiste em "uma linguagem de modelagem que permite representar um sistema de forma padronizada e diagramática" SOMMERVILLE [2011]. Para a implementação foi utilizada a linguagem de programação Python e a biblioteca PyQt4, visando o desenvolvimento da interface gráfica com o usuário. Dessa forma, descrevendo o funcionamento do software, apresentamos a primeira tela de acesso que consiste na "Tela de Introdução"(Figura 1), contendo um botão para adentrar na tela de seleção de linguagem compreensiva, um botão de ajuda e um gif com uma apresentação da ferramenta. A 
VI Congresso Brasileiro de Informática na Educação (CBIE 2017)

Anais do XXIII Workshop de Informática na Escola (WIE 2017)

tela de ajuda (Figura 2) permite o acesso a três tutoriais visando o auxílio na realização das seguinte ações: escolher um nível de linguagem, realizar a avaliação quantitativa e qualitativa. A tela de ajuda também pode ser acessada na tela de seleção de linguagem.

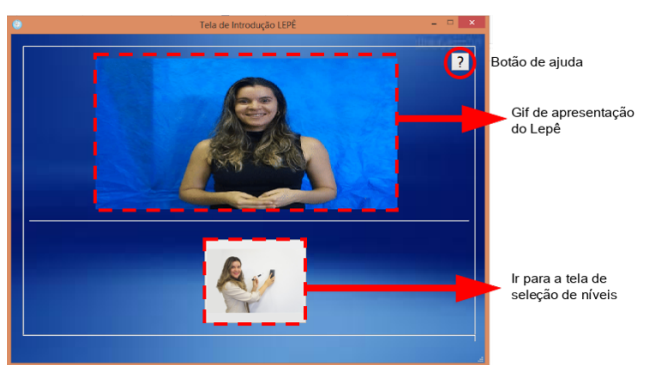

Figura 1. Tela de Introdução

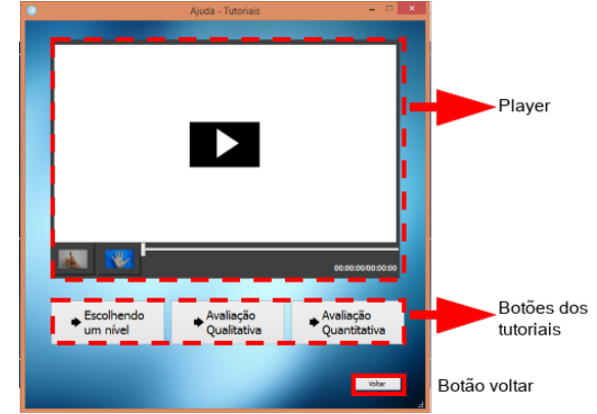

Figura 2. Tela de Ajuda

Na Figura 3 é apresentada a tela de seleção de linguagem compreensiva do LEPÊ, com botões numerados de 1 a $5^{1}$ representando os níveis de linguagem compreensiva. Após a escolha do professor do nível que irá usar, aparece a tela de ensino (Figura 4), onde são evidenciadas uma lista de categorias/conteúdos do nível, uma imagem referente à sinalização, o player de vídeo e o botão de avaliação, que leva para a tela de avaliação quantitativa. Na tela de ensino, tendo em mente que o sujeito surdo é um ser visual, nos botões de categorias, vocabulários, voltar e avaliação, há imagens que indicam suas funções, assim como por escrito se posicionarmos o mouse acima da figura.

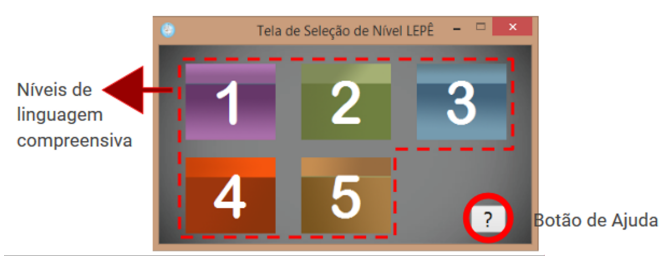

Figura 3. Tela de seleção de linguagem compreensiva

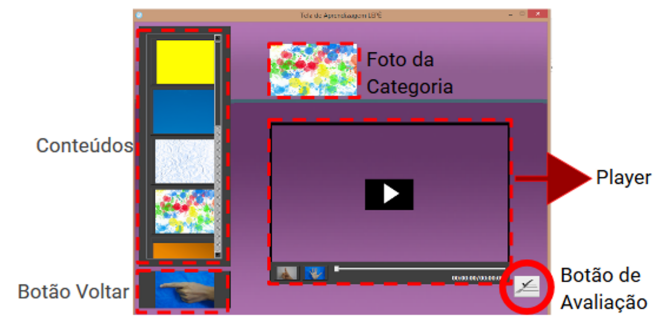

Figura 4. Tela de ensino

A ferramenta dispõe de dois tipos de avaliação que o professor poderá usar quando considerar oportuno: quantitativa e qualitativa. A avaliação quantitativa (Figura 5) contém 4 questões, em cada questão é evidenciado um contexto em vídeo (no caso, a pergunta que o aluno deve responder), com 4 opções de respostas sinalizadas, que constituem-se gifs iniciados quando deslizamos o mouse sob o gif correspondente. Após assistir o vídeo, o aluno(a) deve escolher a alternativa que contém a sinalização do contexto evidenciado no vídeo, clicando no botão correspondente, passando para a próxima questão. Na avaliação qualitativa (Figura 6), fica registrado no software automaticamente o número de questões que o aluno acertou e o nível da avaliação, junto com informações que o professor incluirá: seu próprio nome, o do aluno, e qualquer registro em relação ao desenvolvimento/potencialidades, observações e necessidades do seu aluno.

\footnotetext{
${ }^{1}$ Nível 1: Cores, Dia a Dia, Material escolar, Saudações e cumprimentos; Nível 2: Escolar, Alimentos; Nível 3: Comandos, Pronomes; Nível 4: Adjetivos, Sentimentos; Nível 5: Verbos.
} 


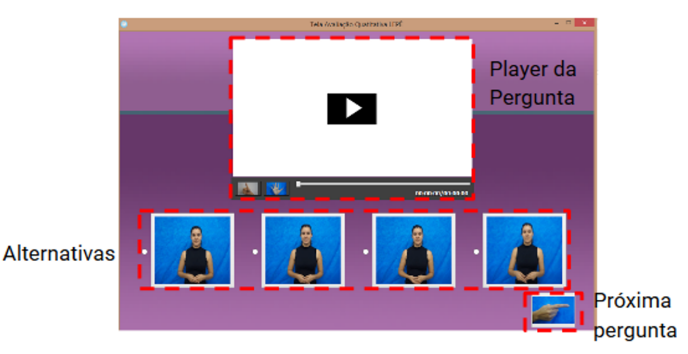

Figura 5. Tela de avaliação quantitativa

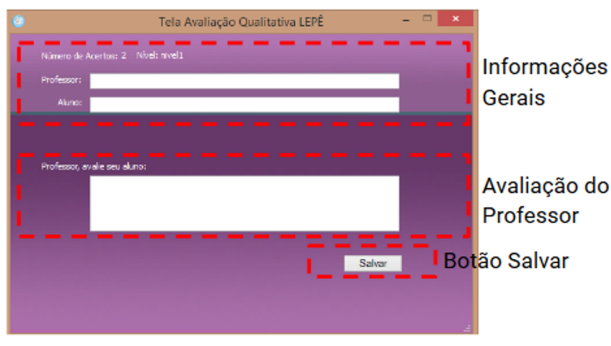

Figura 6. Tela de avaliação qualitativa

\subsection{Aplicabilidade/Funcionalidade}

Em torno da importância do Lepê e sua aplicabilidade nos espaços educacionais, todos os professores entrevistados apontaram que a ferramenta poderia ser positiva na escolarização, no que tange o ensino de Língua de Sinais dos alunos com surdez, bem como, para o trabalho do professor, visto ser visual e apresentar requisitos importantes. Destaca-se o que diz a professora 4 sobre isso:

Prof. 4 - Facilita a compreensão e a memorização, apresenta sinais através das situações do cotidiano. Quanto à aplicabilidade é notório que ela tem aplicabilidade, sim, que é importante tanto para o surdo quanto para o professor principalmente porque é um material muito visual e a partir do pressuposto de que o surdo é um sujeito visual o material é importante para a pessoa surda no aprendizado da Língua de Sinais.

Os participantes destacaram a importância de se criar mecanismos visuais que colaborem com o trabalho do professor nessa empreitada, neste caso, o software Lepê apresenta além das configurações manuais, situações cotidianas que promovem a compreensão e possibilita uma melhor interação do professor com os alunos surdos. Isto porque, conforme já foi visto, é fundamental que a pessoa surda aprenda a Língua de Sinais para a sua escolarização, sendo esta aquisição indispensável para a garantia de uma educação de qualidade, portanto, o Lepê se configura nessa avaliação como útil para esse processo de ensino de Libras no ambiente escolar. Ainda sobre aplicabilidade e funcionalidade da ferramenta proposta, na perspectiva do trabalho docente e estratégias desempenhadas, $\mathrm{o}$ professor 6 atenta algumas observações:

Prof. 6: Levando em consideração que no Atendimento Educacional Especializado, tem se usado muitos joguinhos para aquisição de língua Portuguesa e também de Língua de Sinais. Eu acredito que a ferramenta por ser num ambiente virtual, por ser dinâmica também, ela vai prender muito mais a atenção do aluno na aprendizagem da Libras, muito mais do que dominó, ou outras estratégias e jogos que são utilizados. Além disso, o professor também na medida em que ele vai aprendendo, digamos assim, a utilizar a Língua de Sinais também - mesmo porque existe um número bom de professores, falo pelo menos a partir da experiência que eu tenho onde leciono, que não têm conhecimento em Língua de Sinais -. Então o uso da ferramenta vai possibilitar no professor o aprendizado da língua também. 
VI Congresso Brasileiro de Informática na Educação (CBIE 2017)

Anais do XXIII Workshop de Informática na Escola (WIE 2017)

Segundo LACERDA [2012], o que vemos são professores que dependem de intérpretes que, em sua maioria, não têm formação específica para a docência. Nesse caso, concorda-se com FIGUEIREDO and GUARINELLO [2012], quando afirmam que:

[...] Considerar o aluno surdo na escola regular, por exemplo, vai além de levar em conta a necessidade de um intérprete em sala de aula - muitas vezes proficiente em Língua de Sinais, mas que deixa a desejar no conteúdo.

Resultados de pesquisas têm mostrado - e aqui destacam-se as impressões de BORGES and NOGUEIRA [2017] em pesquisa com professores ouvintes de diversas disciplinas que possuem alunos surdos - que a maioria dos professores alega não possuir formação para receber o aluno em suas aulas. Contudo, mostram-se ser favoráveis ao fato desses alunos frequentarem suas aulas e destacam depender do intérprete. Tais fatos ocorrem, muitas vezes, pelo professor não estar preparado para atender às diferenças metodológicas e linguísticas do aluno surdo e, além disso, muitos não os consideram como sua responsabilidade. SCHEMBERG et al. [2009] consideram que:

Para grande parte de professores que atuam com alunos surdos, sobretudo no ensino regular e, para a grande parte dos pais, a cópia é o meio pelo qual o aluno/filho demonstra estar se apropriando de determinado conteúdo escrito. Torna-se, assim, uma simulação de compreensão, tanto para os pais, quanto para o professor que, ao deparar-se com as cópias do filho/aluno, têm a impressão de que está havendo compreensão, da mesma forma que por meio da cópia o filho/aluno simula estar se apropriando do conteúdo. Aprender a escrever, então, no contexto da surdez, seria memorizar a escrita das palavras através da cópia. Essa concepção de escrita ligada apenas à escola é bastante difundida entre a população de modo geral e é decorrente do processo de alfabetização pelo qual passamos, como algo individual.

Diante dessa realidade, identificou-se mais uma possibilidade de uso da ferramenta, com base na avaliação dos especialistas, isto é, o Lepê poderá ser utilizado pelo docente que ainda não conhece Língua de Sinais, embora seja necessário destacar que sem a mediação do professor para o uso do Lepê levando em consideração o quadro situacional que destacamos não é suficiente, assim como também a sua fluência em Língua de Sinais, devendo este buscar esse estudo e ainda convivência com a comunidade surda. Nesse sentido, focando o que tange a realização dessas experiências de mediação professor/aluno segundo VYGOTSKY [2000], a realização dessas experiências de interação é importante para que o aluno possa elaborar conceitos e cabe ao professor organizar estratégias para que o aluno surdo alcance a organização dos processos mentais. A Professora 9 destacou possibilidades do Lepê:

Prof. 9: Olha, acredito que é algo bem novo. Quando eu estava estudando educação de surdos para a minha pesquisa eu achava muito material sobre aquisição de Língua Portuguesa, mas nada de Libras. A realidade é essa: surdos chegam na escola e não sabem Libras e são automaticamente inseridos no Português, muitas vezes, sem entender muita coisa. A gente sabe que para os surdos os estímulos visuais são muito importantes e, nesse caso, eu percebi muitos estímulos. Além disso, a possibilidade de fazer os registros de acompanhamento qualitativo é muito bom e na minha experiência me ajudou, nesse pouco tempo, a avaliar melhor o meu aluno. 
VI Congresso Brasileiro de Informática na Educação (CBIE 2017)

Anais do XXIII Workshop de Informática na Escola (WIE 2017)

Considera-se importante destacar que no momento de escolarização para surdos as estratégias visuais colaboram na produção de sentido, uma vez que é através do processamento da informação visual que haverá a realização de vários atos interpretativos ELIAS and KOCH [2006]. Nesse caso, foram destacados que a aplicabilidade da ferramenta teria mais um fator importante, que são as características visuais mais próximas possível da realidade e das experiências das pessoas com surdez. Dentre as avaliações da ferramenta, destacam-se as opiniões dos professores 12 e 07:

Prof. 12: Eu acredito que esse material é diferenciado pois, além de você estar vendo o outro, também está vendo o contexto, está vendo expressões, então não é uma coisa mecânica. É diferente do demais, ele tem essa apresentação do ser humano que os outros não trazem.

Prof. 07: Vejo diferencial, por conta também da riqueza do recurso imagético, da sinalização com o contexto, que é uma representação de onde o sinal pode ser utilizado. No caso da ferramenta tem o contexto, onde pessoas reais aparecem sinalizando e fica algo bem próximo a realidade.

Nota-se nos fragmentos destacados que os professores atentaram para o uso de contexto nos vídeos do Lepê, como diferencial positivo no processo de aquisição do aluno com surdez. Nesse sentido, percebemos o quão trazer essas vivências e contextualizá-las contém grande importância, já que "As vivências, os registros, a comunicação, a utilização das experiências são elementos da subjetividade também eles configurados e delimitados a partir da realidade objetiva, do fenômeno social construído historicamente"'[GONÇALVES and FURTADO, 2016]. Sobre isso, FERNANDES [1998] comenta acerca das propostas e estratégias comumente trabalhadas:

\footnotetext{
$\mathrm{Na}$ área da surdez, é comum nos depararmos com propostas de ensino que separam a linguagem de seu conteúdo axiológico e vivencial, desconsiderando seu contexto de produção constituído por falantes com experiências cotidianas diferenciadas e reduzindo-a a um sistema abstrato de formas prontas. De maneira geral, elegem-se como objeto de trabalho palavras ou enunciados isolados, delimitados por uma progressão fonética preestabelecida, organizada a partir de critérios do nível de complexidade do ponto de vista de sua produção fonoarticulatória e de sua percepção visual pelo surdo, que acaba por treinálos tendo o espelho como interlocutor. Mesmo quando são eleitos enunciados um pouco mais complexos, do ponto de vista de sua organização sintática, o objetivo não é ainda a língua viva, mas a preocupação em apresentar sua estruturação gramatical, garantindo a fixação da ordem correta das palavras, como se fosse possível prever os caminhos sintáticos a serem percorridos no processo de interação verbal.
}

Assim, importa destacar o que DORZIAT et al. [2011] apontam como a necessidade de que os alunos surdos têm em contemplar suas aprendizagens de significados, ou seja, de vivências e experiências em contextos próprios. Por isso, a ferramenta leva em consideração esse quadro e contempla casos reais com contextos. A importância disso consiste em encorajar a utilização de sinais, mostrando que o sujeito surdo está sendo compreendido. O objetivo principal é que o participante produza sinais ou sentenças na Língua de Sinais de forma natural. SOUSA et al. [2009] destaca que a construção do 
sentido é mediada pela linguagem em momentos de interação e que é nessa participação que o indivíduo está construindo possibilidades e sentido pleno ao processo de aquisição.

Diante do exposto, os professores destacaram a possibilidade de usabilidade e apontaram que o Lepê parece ser uma proposta rica em termos de estratégias para ensino de surdos e para professores que não sabem Libras. Além disso, por possuir conceitos e possibilidades visuais, com contextos próximos do mundo real, a ferramenta comporta boas possibilidades de ser um instrumento de uso no cotidiano escolar. Por fim, importa destacar também que não houve diferenças entre as opiniões dos professores dos dois municípios. Acreditamos que este fato ocorre porque a realidade/necessidades que abrangem a educação de surdos têm sido próximas, assim professores apontam características semelhantes em suas avaliações.

\section{Conclusões}

Pode-se perceber que a ferramenta poderá constituir-se como importante estratégia pedagógica no que tange ao processo de trabalho/mediação do professor no ensino da Língua de Sinais e na construção do Pensamento e da Linguagem, visto que o Pensamento e a Linguagem não se apresentam como uma fusão linear entre uma fusão e outra e, tampouco são independentes, trata-se nesse caso de uma relação histórica e dialeticamente construída que se configura através da atividade do sujeito no mundo.

As experiências com a ferramenta mostraram que os participantes encontraram possibilidades de uso no cotidiano escolar do Lepê e que, de forma geral eles tiveram opiniões positivas, indicando que o Lepê poderá contribuir com o processo atual existente na Educação de surdos. Além disso, foram destacados aspectos importantes em relação ao uso de contextos, às "sinalizações reais", realizadas por seres humanos e por possuir características visuais, sinalizadas como essenciais para o trabalho com este público alvo.

A sinalização com contexto, através do qual o aluno surdo poderá visualizar situações onde a sinalização pode ser empregada, foi tida como ponto fudamental devido à falta de propostas de ensino na área da surdez visando essa contextualização, assim, alunos surdos têm o aprendizado comprometido apenas com uma linguagem apresentada a partir de formas prontas, cuja preocupação está na estrutura gramatical. Ao contextualizar a sinalização, o aluno tem a possibilidade de ter uma experiência mais realista no aprendizado, sendo capaz de identificar contextos de uso da sinalização.

A falta de ferramentas virtuais para o auxílio no ensino de Libras em conjunto com a falta de abordagens na educação de surdos que visem a contextualização apontam a necessidade de maior atenção na educação dos surdos, principalmente dos que são filhos de pais ouvintes, que muitas vezes chegam à escola sem conhecimento de Libras e na própria escola não encontra propostas de ensino adequadas, o que é fundamental para a aquisição da linguagem e inserção do sujeito no mundo. Por fim, pode-se entender que a busca de novas possibilidades, por meio de uma ferramenta que funciona como um software e, aliado ao trabalho docente, poderá proporcionar uma nova possibilidade para as crianças surdas em fase de escolarização e ingressantes nesse universo linguístico.

\section{Referências}

ANDRADE, C. C. and HOLANDA, A. F. (2010). Apontamentos sobre pesquisa qualitativa e pesquisa empírico-fenomenológica. Estud. psicol.(Campinas), 27(2):259-268. 
VI Congresso Brasileiro de Informática na Educação (CBIE 2017)

Anais do XXIII Workshop de Informática na Escola (WIE 2017)

BORGES, F. A. and NOGUEIRA, C. M. I. (2017). O ensino e a aprendizagem de matemática para surdos inclusos: O que dizem os intérpretes de libras? Educação Matemática em Revista-RS, 2(17).

DORZIAT, A., ARAÚJO, J. R., and SOARES, F. P. (2011). O direito dos surdos à educação: que educação é essa? Estudos surdos: diferentes olhares. Porto Alegre: Mediação, pages 19-60.

ELIAS, V. M. and KOCH, I. V. (2006). Ler e compreender os sentidos do texto. São Paulo: Contexto.

FERNANDES, E., Correia, C. d. C., and Fernandes, E. (2005). Bilinguismo e surdez: a evolução dos conceitos no domínio da linguagem. FERNANDES, E. Surdez e bilinguismo.

FERNANDES, S. d. F. (1998). Surdez e linguagens: é possível o diálogo entre as diferenças? $\mathrm{PhD}$ thesis, Universidade Federal do Paraná.

FIGUEIREDO, L. C. and GUARINELLO, A. C. (2012). Literatura infantil e a multimodalidade no contexto de surdez: uma proposta de atuação. Revista Educação Especial, 26(45):175-192.

GESSER, A. (2012). O ouvinte e a surdez: sobre ensinar e aprender a libras. São Paulo: Parábola Editorial.

GONÇALVES, M. d. G. M. and FURTADO, O. (2016). A perspectiva sócio histórica: uma possibilidade crítica para a psicologia a para a educação. In A dimensão Subjetiva do Processo Educacional: uma leitura Sócio Histórica. Editora Cortez, São Paulo.

KARNOPP, L. B. and PEREIRA, M. C. d. C. (2004). Concepções de leitura e de escrita e educação de surdos. Leitura e escrita no contexto da diversidade. Porto Alegre: Mediação, page 35 .

LACERDA, C. B. F. d. (2012). O intérprete de língua brasileira de sinais (ils). LODI, Ana Cláudia Balieiro; MELO, Ana Dorziat Barbosa de; FERNANDES, Eulália (Org.). Letramento, bilinguismo e educação de surdos. Porto Alegre: Mediação.

LI, M. and SMIDTS, C. S. (2003). A ranking of software engineering measures based on expert opinion. IEEE Transactions on Software Engineering, 29(9):811-824.

MACIEL, A. and CARVALHO, E. (2010). Five-framework for an integrated voice environment. In Proceedings of International Conference on Systems, Signal and Image Processing, Rio de Janeiro.

PEIXOTO, R. C. (2006). Algumas considerações sobre a interface entre a língua brasileira de sinais (libras) e a língua portuguesa na construção inicial da escrita pela criança surda. Cad. Cedes, 26(69):205-229.

QUADROS, R. d. (2005). O 'bi’em bilinguismo na educação de surdos. Surdez e bilinguismo. Porto Alegre: Mediação, 1:26-36.

SCHEMBERG, S., GUARINELlO, A. C., and SANTANA, A. P. d. O. (2009). As práticas de letramento na escola e na família no contexto da surdez: reflexões a partir do discurso dos pais e professores. Rev. bras. educ. espec, 15(2):251-268.

SOMMERVILLE, I. (2011). Engenharia de software. Pearson Prentice Hall.

SOUSA, W. P. d. A. et al. (2009). A construção da argumentação na língua brasileira de sinais: divergência e convergência com a língua portuguesa.

VYGOTSKY, L. (2000). A construção do Pensamento e da Linguagem. São Paulo: Martins Fontes. Tradução Paulo Bezerra. 